\title{
AN EXPERIMENTAL STUDY ON SLIDING RIGID BODY IN WATER DURING EARTHQUAKES
}

\author{
By Tatsuo UWABE* and Norihiro HIGAKI**
}

\begin{abstract}
Shaking table tests of model blocks were conducted to study sliding behavior of a rigid body in the water during earthquakes. The accelerations and hydrodynamic pressures on the model block decreased instantaneously on set of sliding and remained the same levels during sliding. The static and dynamic coefficients of friction obtained from the vibration tests in consideration of the added mass of which inertia force corresponded to the hydrodynamic pressures on the model block were almost the same values as those measured by Euler's method. A method to estimate the displacements of the sliding block during earthquakes was presented. The displacement calculated from the horizontal and vertical base accelerations showed relatively good agreement to the measured value.
\end{abstract}

\section{INTRODUCTION}

Many kinds of the investigation for the seismic stability of port facilities have been done in the Tokai area where a large earthquake is concerned to occure in the near future. In order to take efficient eartquake prepardness it is necessary to know how each facility is damaged, that is to know the damage deformation, such as a residual sliding displacement of gravity type structures. A calculation method of a sliding displacement during earthquakes is desired to be discussed in full detail.

In his 1965 Rankine Lecture Newmark ${ }^{1)}$ described simple concepts for computing the displacement of a sliding mass in an embankment subjected to earthquake accelerations. Additional studies of the sliding mass during earthquakes have been made ${ }^{2)}$ (4). In Japan Fujino, Sasaki and Hakuno ${ }^{5)}$ reported the slip of a friction controlled mass excited by earthquakes. Toki, Sato and Miura ${ }^{6}$ studied a separation and a sliding between soils and structures during strong motions using a joint element. In the past studies values of static and dynamic coefficients of friction and the relation between them were not discussed in detail, and the validity of the calculation methods for the sliding displacement during earthquakes was not checked except the study of Sim and Berrill ${ }^{4}$. The sliding of gravity type structures in the water during earthquakes was not analyzed in the past studies. The present paper is concerned with these points that were not discussed in the past studies. This paper accordingly describes a sliding behavior of a simple rigid body model in the water, static and dynamic coefficients of friction and verification of the validity of the calculation method for the sliding displacement during earthauakes based on shaking table tests.

\footnotetext{
* Member of JSCE, Chief of Earthquake Disaster Prevention Laboratory, Structures Division, Port and Harbour Research Institute, Ministry of Transport (3-1-1, Nagase, Yokosuka, Japan)

** Member of Earthquake Disaster Prevention Laboratory, ditto
} 


\section{RIGID BODY MODEL}

Four kinds of rigid body models were used in this study. These models were named A, B 1, B 2, C and $\mathrm{D}$ model. Table 1 shows the unit weight (rounded to one decimal), the dimension, the weight (the weight that includes pickups is also shown) and the kind of test. The rigid body model $\mathrm{A}$ is a low model that was made to know the sliding behavior clearly. The rigid body model $\mathrm{D}$ is also low and was used for preparatory tests to select a proper accelerometer.

\section{SLIDE TESTS FOR STATIC COEFFICIENT OF FRICTION}

Fig. 1 shows a slide test of a rigid body model to measure static coefficients of friction. A pulling load was a drop of shots whose diameter is about $2 \mathrm{~mm}$ in a bucket shown in the left side of Fig. 1 . The contact surface between the model and the acrylic sheet is dry or wet. The water was put to $1 \mathrm{~cm}$ from the acrylic sheet surface for the wet contact suface. A full infiltration of the water between the model and the acrylic sheet was confirmed before the test.

According to test results the average static coefficients of friction were 0.52 for the model B 1 and 0.63 for model $\mathrm{C}$ (both of standard deviations were 0.02$)$. As the static coefficient of friction for

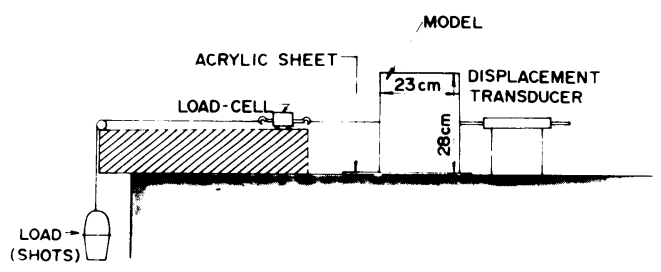

Fig. 1 Slide test setup. the model B 1 with the wet surface, at an average of 4 times of tests were 0.52 , it is considered that there is no change of the static coefficients of friction in surface conditions.

\section{EULER'S TEST FOR STATIC AND DYNAMIC COEFFICIENT OF FRICTION}

\section{(1) Euler's test}

The well-known Euler's test gives static and dynamic coefficients of friction from a sliding mass on a slope. The coefficients of friction $\mu_{s}$ static and $\mu_{d}$ dynamic are as follows ${ }^{7)}$.

$$
\begin{aligned}
& \mu_{s}=\tan \theta_{s} \\
& \mu_{d}=\tan \theta_{s}-\frac{2 \cdot S}{g \cdot t_{s}^{2} \cdot \cos \theta_{s}}
\end{aligned}
$$

In these equations $\theta_{s}$ is the angle of inclination to start sliding, $S$ is a distance of sliding down, $t_{s}$ is the time to slide distance of $S$ and $g$ is acceleration of gravity.

Fig. 2 shows the Euler's test setup. The inclined board was pushed up by a oil jack to make a rigid body model start sliding. Two kinds of tests, the rigid body model B 2 on the acrylic sheet (No. 1) and the rigid body model B 1 on the mortar board (No. 2) were examined

The angle of inclination was obtained from measuring the sliding direction of acceleration of gravity by an accelerometer on the inclined board. The time for the rigid body model to slide certain distance was measured as follows. An instance to start sliding was detected by the displacement transducer on the top of the inclined board shown in Fig. 2. An instance to come to end of sliding

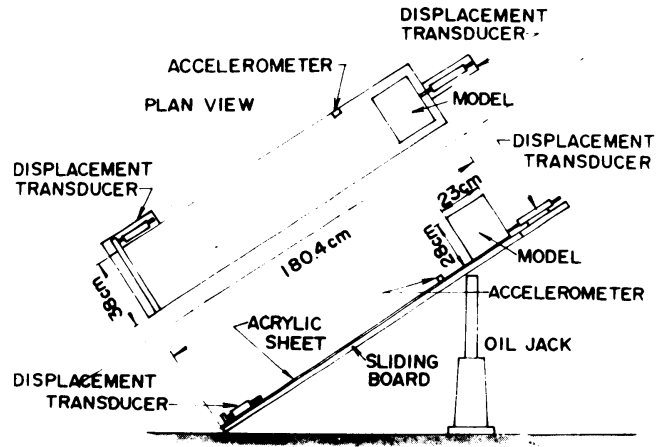

Fig. 2 Euler's test setup. 
Table 2 Results of Euler's test (No. 1).

\begin{tabular}{|c|c|c|c|c|c|}
\hline No. & $\begin{array}{c}\text { Angle of } \\
\text { sliding board } \\
\text { (Degree) }\end{array}$ & $\begin{array}{c}\text { Time } \\
\text { elapsed } \\
(\mathrm{s})\end{array}$ & $\begin{array}{c}\text { Velocity } \\
(\mathrm{m} / \mathrm{s})\end{array}$ & $\frac{\text { Coef. of }}{\text { Static }}$ & $\frac{\text { friction }}{\text { Dynamic }}$ \\
\hline $\begin{array}{r}1 \\
2 \\
3 \\
4 \\
5 \\
6 \\
7 \\
8 \\
9 \\
10 \\
11 \\
12 \\
13\end{array}$ & $\begin{array}{l}29.0 \\
29.9 \\
29.6 \\
30.1 \\
29.6 \\
27.8 \\
33.1 \\
29.8 \\
29.9 \\
29.9 \\
29.8 \\
30.9 \\
31.0\end{array}$ & $\begin{array}{l}1.57 \\
1.43 \\
1.62 \\
1.31 \\
1.48 \\
2.20 \\
1.17 \\
1.48 \\
1.51 \\
1.47 \\
1.49 \\
1.35 \\
1.44\end{array}$ & $\begin{array}{l}0.96 \\
1.05 \\
0.93 \\
1.15 \\
1.01 \\
0.68 \\
1.28 \\
1.01 \\
0.99 \\
1.02 \\
1.01 \\
1.11 \\
1.04\end{array}$ & $\begin{array}{l}0.55 \\
0.58 \\
0.57 \\
0.58 \\
0.57 \\
0.53 \\
0.65 \\
0.57 \\
0.58 \\
0.58 \\
0.57 \\
0.60 \\
0.60\end{array}$ & $\begin{array}{l}0.41 \\
0.40 \\
0.44 \\
0.37 \\
0.41 \\
0.46 \\
0.39 \\
0.41 \\
0.42 \\
0.41 \\
0.41 \\
0.40 \\
0.43\end{array}$ \\
\hline \multicolumn{4}{|r|}{$\begin{array}{c}\text { Average } \\
\text { Standard } \\
\text { deviation }\end{array}$} & $\begin{array}{l}0.58 \\
0.03\end{array}$ & $\begin{array}{l}0.41 \\
0.02\end{array}$ \\
\hline
\end{tabular}

Table 3 Results of Euler's test (No.2)

\begin{tabular}{|c|c|c|c|c|c|}
\hline No. & $\begin{array}{c}\text { Angle of } \\
\text { sliding board } \\
\text { (Degree) }\end{array}$ & $\begin{array}{c}\text { Time } \\
\text { elapsed } \\
\text { (s) }\end{array}$ & \begin{tabular}{|c|} 
Velocity \\
$(\mathrm{m} / \mathrm{s})$
\end{tabular} & $\frac{\text { Coef. of }}{\text { Static }}$ & $\frac{\text { friction }}{\text { Dynamic }}$ \\
\hline \begin{tabular}{l|}
1 \\
2 \\
3 \\
4 \\
5 \\
6
\end{tabular} & $\begin{array}{l}36.9 \\
32.2 \\
32.8 \\
35.6 \\
29.8 \\
32.9\end{array}$ & $\begin{array}{l}1.50 \\
1.71 \\
2.01 \\
1.47 \\
1.84 \\
1.42\end{array}$ & $\begin{array}{l}0.97 \\
0.85 \\
0.73 \\
0.99 \\
0.79 \\
1.03\end{array}$ & $\begin{array}{l}0.75 \\
0.63 \\
0.65 \\
0.71 \\
0.57 \\
0.66\end{array}$ & $\begin{array}{l}0.58 \\
0.51 \\
0.56 \\
0.54 \\
0.47 \\
0.47\end{array}$ \\
\hline \multicolumn{4}{|r|}{$\begin{array}{c}\text { Average } \\
\text { Standard } \\
\text { deviation }\end{array}$} & $\begin{array}{l}0.66 \\
0.06\end{array}$ & $\begin{array}{l}0.52 \\
0.04\end{array}$ \\
\hline
\end{tabular}

distance was found out by the displacement transducer's detection of a contact between a rigid body model and a rod on the lower part of the inclined board. The time to slide a distance was calculated from records of the two displacement transducers and a paper speed of a recorder.

(2) Test results

Table 2 shows test results of the model B 2 on the acrylic sheet, and Table 3 shows those of the model $\mathrm{B} 1$ on the mortar board. As shown in Tables 2 and 3 the dynamic coefficient of friction is smaller than static one. A dynamic to static ratio is about 0.7 on the acrylic sheet and about 0.8 on the mortar board. The differnce between dynamic and static coefficients of friction for the acrylic sheet is larger than that for the mortar board.

\section{SHAKING TABLE TESTS OF SLIDING RIGID BODY MODEL IN WATER}

\section{(1) Models and instruments}

Table 4 shows accelerometers used in this test. A water-proof inductive-type displacement transducer whose ampltude limit is $\pm 10 \mathrm{~mm}$ was used to measure the sliding displacement of a rigid body model. A strain-gauge type pressure gauge (rated capacity is $0.5 \mathrm{kgf} / \mathrm{cm}^{2}(49 \mathrm{kPa})$ and weight is $230 \mathrm{gf})$ was used to measure the hydrodynamic pressure on the model. Figures 3,4 and 5 show models and pickups. The used models are A, B 2 Table 4 Accelerometer.

\begin{tabular}{l|l|c|c|c|c|c}
\hline Symbol & \multicolumn{1}{|c|}{ Type } & $\begin{array}{c}\text { Amplitude } \\
\text { 1imit }\end{array}$ & Size $(\mathrm{mm})$ & $\begin{array}{c}\text { Weight } \\
\text { (gf) }\end{array}$ & $\begin{array}{c}\text { Frequency } \\
\text { range }(\mathrm{Hz})\end{array}$ & \\
\hline A1 & Strain-gauge & $\pm 10 G$ & $18 \times 18 \times 24$ & 40 & $0-150$ & Water-proof \\
A2 & Semi-conductor & $\pm 5 G$ & $3.7 \times 3.7 \times 9$ & 2 & $0-80$ & \\
& element & $\pm 2 G$ & $46 \times 46 \times 109$ & 530 & $0-370$ & \\
A3 & Servo & \pm 26 & 17 & $0-350$ & \\
A4 & Strain-gauge & $\pm 10 G$ & $16 \times 16 \times 16$ & 17 & Water-proof \\
A5 & Strain-gauge & $\pm 10 G$ & $18 \times 18 \times 24$ & 40 & $0-60$ & Water \\
\hline
\end{tabular}
and $\mathrm{D}$ shown in Table 1.

(2) Shaking table and type of excitation

The shaking table of the Port and Harbour Research Institute, Ministy of Transport was used. A glass-sided rectangular box on the shaking table is $5 \mathrm{~m}$ long, $1.5 \mathrm{~m}$ wide and $1.5 \mathrm{~m}$ heigh. As a duration time of a excitation was short, and as it was considered that the distance between the model and the wall in exciting directions is long enough, a wave absorber was not placed in front of the wall in exciting directions.

Types of excitation are a periodic 10 -sine-wave and a earthquake wave. The 10 -sine-wave means a periodic excitation of 10 -wave with a certain frequency and a uniform amplitude. The frequency of 10-sine-wave excitation was selected from $5,7,10,20$ and $30 \mathrm{~Hz}$. The amplitude of the 10-sine-wave was given to be strong enough to cause model sliding. The wave used for the earthquake excitation is a strong motion earthquake record (S-1210, E-W component) obtained on the rock at Ofunato port in 1978-Miyagiken-oki earthquake. The duration time of the record was not modified, and the amplitude was scaled to cause model sliding.

(3) Selection of accelerometer used in tests 


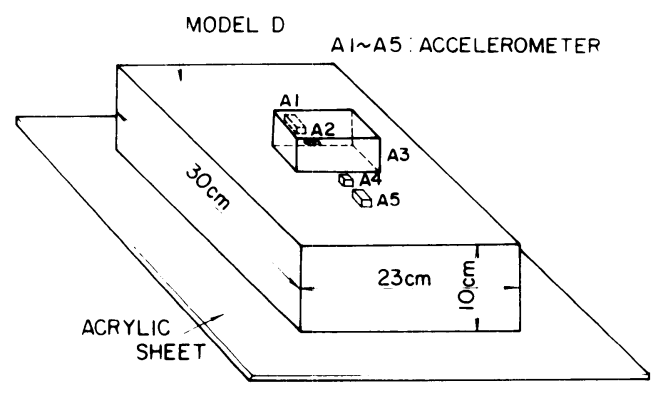

Fig. 3 Model D and pickups.

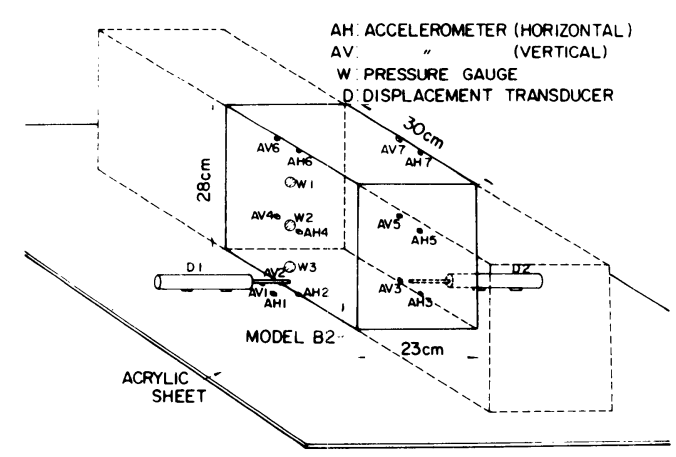

Fig. 5 Model B 2 and pickups.

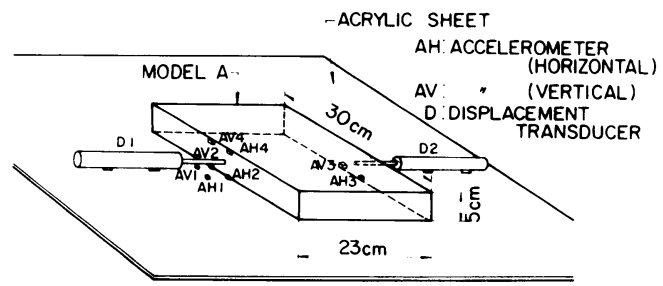

Fig. 4 Model A and pickups.



Fig. 6 Observed waveforms of accelerometer

A flat response range of the frequeucy was uncertain to measure the accurate acceleration waveform of sliding model. Then a preparatory test to select a proper accelerometer was conducted for the 5 kinds of accelerometers whose frequency range is different as shown in Table 4.

The accelerations of 5 kinds of accelerometers on the model D shown in Fig. 3 were compared by a periodic excitation test. Fig. 6 shows a test result. Solid lines shown in Fig. 6 are the waveforms of a accelerometer A 3 whose upper limit of a frequency range is highest and dotted lines are those of other accelerometers. Accoridng to Fig. 6 there was no difference in the acceleration waveform of the accelerometer whose upper limit of frequency range is more than $150 \mathrm{~Hz}$. Therefore it was decided that the accelerometer A 1 whose frequency range is from 0 to $150 \mathrm{~Hz}$ was used for this study. The accelerometers shown in Figures 4 and 5 are all $\mathrm{A} 1$.

\section{RESULTS OF SHAKING TABLE TESTS}

\section{(1) Slide of rigid body model during vibration}

Fig. 7 shows test results of model A on the acrylic sheet by 10-sine-wave excitation with a frequency of $10 \mathrm{~Hz}$. According to the acceleration waveforms of model $\mathrm{A}$ an amplitude of model accelerations decreased instantaneously at the moment to cause a sliding displacement and remained the same level during sliding. The reason why accelerations of the model decrease is a change of coefficient of friction from static to dynamic. A full discussion about this is described after. Though the acceleration waveforms of models on set of the first sliding are mentioned above, the acceleration waveforms on set of the second sliding was not same as the first one. In this report the first sliding of a rigid body model was described, and the next step to investigate the complicated behavior on and after the second sliding will be studied in the future.

Fig. 8 shows the test results of model $B 2$ in the water on the acrylic sheet by 10-sine-wave excitation 


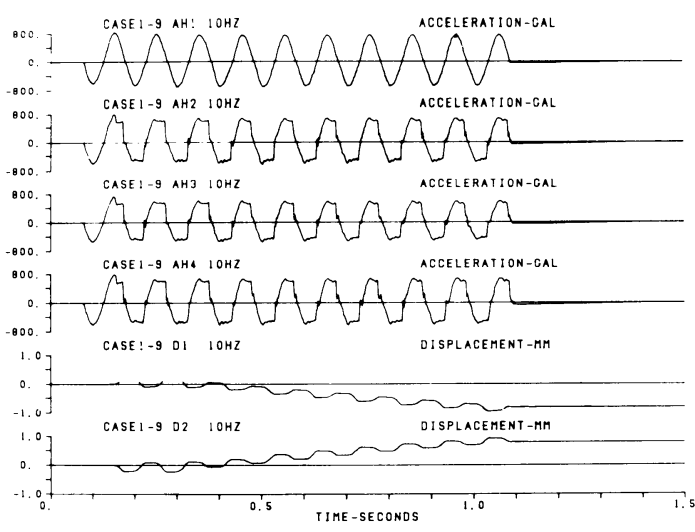

CASE:-9 AV! :OHZ ACCELERATION-GAL

COA

CASE: - 9 AV2 $10 \mathrm{HZ}$

ACCELERATION-GaL

(1)

CASEI-9 AVB :OH

ACCELERATION-GAL

(1)

SASE:-9 AVA $10 \mathrm{HZ}$

ACCELERATION-GAL

(1)

Fig. 7 Results of sliding test (Model A)



Fig. 9 Ratio of hydrodynamic pressure after to before sliding.

with a frequency of $5 \mathrm{~Hz}$. These waveforms of hydrodynamic pressures show same tendency in waveforms of horizontal accelerations.
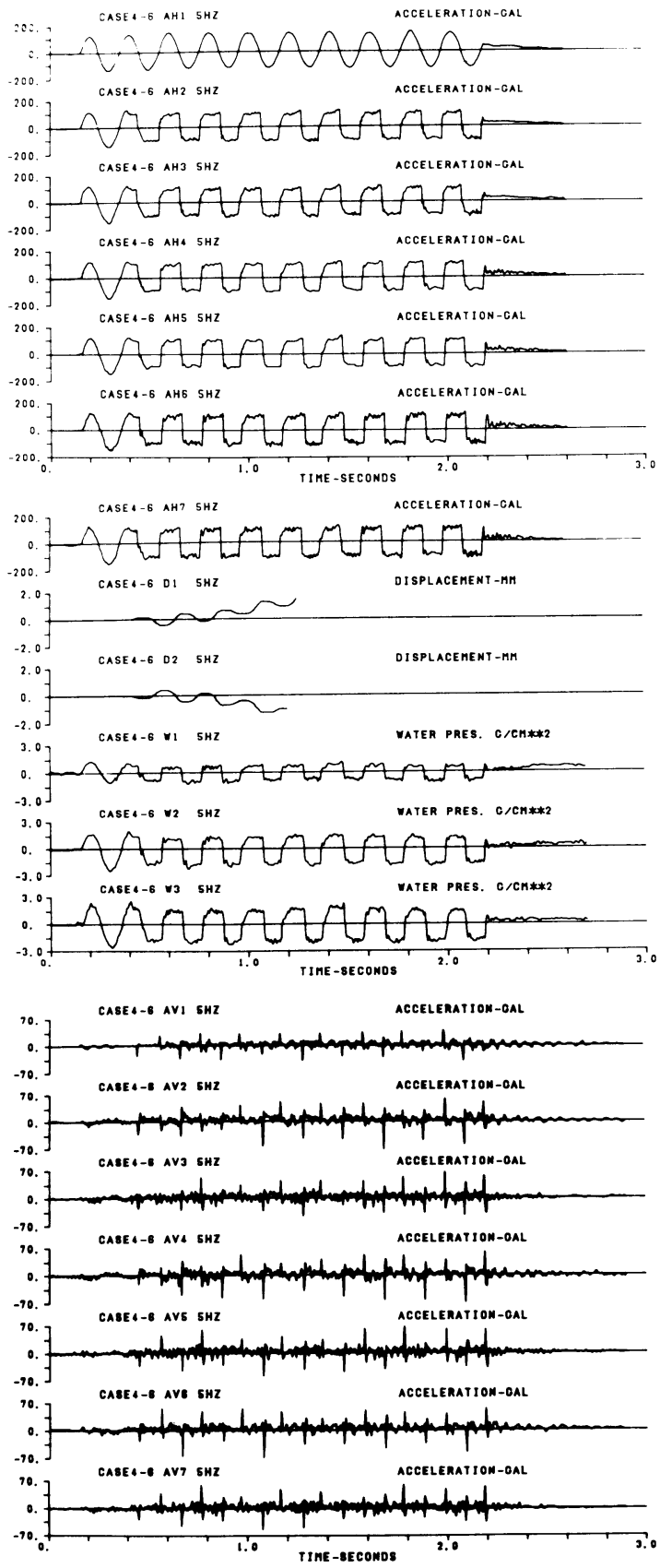

Fig. 8 Results of sliding test (Model B 2).

(2) Hydrodynamic pressure on rigid body model

The amplitude of hydrodynamic pressures decreased instantaneously at the moment of sliding and remained the same level during sliding as same as the accelerations. Then hydrodynamic pressures on set of sliding were compared with those during sliding. Fig. 9 shows ratios of hydrodynamic pressures during sliding to those at the instant of sliding. According to Fig. 9 the decreasing rates are from 20 to $30 \%$ and are almost same at each height.

(3) Coefficient of friction obtained from shaking table tests 




Fig. 10 Sliding block under horizontal sine excitation.

Fig. 10 shows a concept of a sliding rigid body subjected to a periodic loading without a vertical motion. As shown in Fig. 10 the rigid body starts sliding by an inertia force that is equal to a static friction force, and continues sliding under a dynamic friction force that is smaller than static one until a relative velocity becomes zero. Though it was considered that coefficients of friction de-

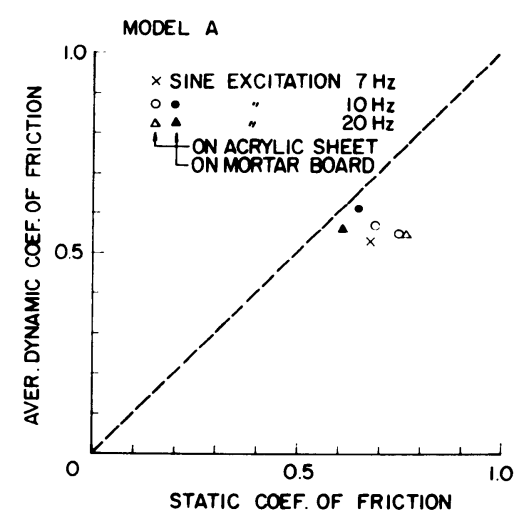

Fig. 11 Static and dynamic coef. of friction (Model A)



Fig. 12 Static coef. of friction (Model B 2 without water). crease continuously from static to dynamic values with increase of a relative velocity and approach a certain value $^{7)}$, it is assumed in this report that the coefficients of friction decrease discontinuously from static to dynamic value and remain dynamic value during sliding. As described before the model accelerations decreased instantaneously at the moment to cause a sliding displacement and remained the same levels during sliding. Therefore the above assumption is likely valid to calculate a sliding displacement. The calculation method of a sliding displacemeht is discussed in next chapter.

Next, coefficients of friction based on the above assumption were obtained from shaking table tests. The test results of model A were firstly discussed. The static coefficients of friction were calculated from the maximum horizontal accelerations and the vertical accelerations. The average dynamic coeffcients of friction were calculated from the average of horizontal accelerations during sliding. Fig. 11 shows static and average dynamic coefficient of friction of a model on the acrylic sheet or on the mortar board. According to Fig. 11 the ratio of dynamic to static coefficient of friction is about $70 \%$ on the acrylic sheet and about $90 \%$ on the mortar board.

Secondly test results of the model B 2 with the water depth of $25 \mathrm{~cm}$ and without the water are described. In calculations of coefficients of friction the added mass of which inertia force corresponds to twice the hydrodynamic pressure on a side wall of the model was considered. Fig. 12 shows static coefficients of friction for model B 2 with and without the water versus input maximum accelerations. Static coefficients of friction for model B 2 with the water are a little smaller than those without the water. It was supposed that one of reasons to cause this differnce was the characterictics of the pressure gauge and the accelerometer (An accelerometer whose rated capacity is $\pm 10 \mathrm{G}(9800 \mathrm{Gal})$ was used in case of small 
input accelerations from restriction of the frequency characteristics). Both coefficients of friction obtained from slide tests in Chapter 3 and Euler's tests shown in Fig. 12 are likely same as those without the water. In view of the results so for described above it was concluded that the sliding behavior of a rigid body in the water was able to be discussed in consideration of the added mass that is twice the hydrodynamic pressures on a side wall of a rigid body divided by acceleration of gravity.

Fig. 13 shows static and dynamic coefficient of friction obtained from shaking table tests. In Fig. 13 the results of Euler's tests are also shown. The ratios of dynamic to static coefficient of friction for Euler's tests were slightly small compared with those of shaking table tests.

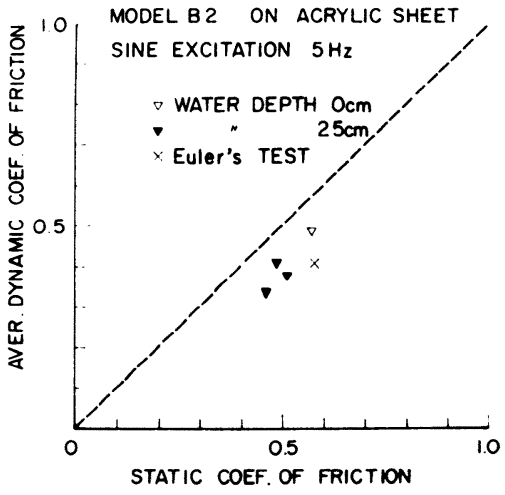

Fig. 13 Static and dynamic coef. of friction (Model B 2).

\section{DISPLACEMENT COMPUTING METHOD OF SLIDING RIGID BODY DURING EARTHQUAKES}

\section{(1) Concepts for displacement computing method of sliding rigid body}

In this report the displacement of a sliding rigid body during earthquakes was computed from the concepts shown in Fig. 10. In Fig. $10 A(t)$ is the input acceleration, $\mu_{s}$ and $\mu_{d}$ are the static and dynamic coefficient of friction and $g$ is acceleration of gravity. A rigid body starts sliding when $A(t)$ is equal to $\mu_{s} \cdot g$. As the acceleration of the rigid body becomes $\mu_{d} \cdot g$ during sliding, the difference between the input acceleration and the rigid body acceleration is caused. This difference of accelerations between the foundation and the rigid body during sliding gives a relative displacenemt. The relative displacement is obtained from the integral of the relative velocity that is the integral of the difference of accelerations between the foundation and the rigid body during sliding.

The relative displacements of a sliding rigid body were calculated under the following.

i) The input motions are horizontal and vertical accelerations (AH 1, AV 1).

ii ) Coefficients of friction obtained in Chapter 6 were used.

iii) The first sliding of 10 -sine-wave excitation was discussed.

iv) The effect of the water on a sliding rigid body was evaluated by the added mass that is twice the hydrodynamic pressures on a side wall of a rigid

Table 5 Calculated and observed relative displacement.

\begin{tabular}{|c|c|c|c|c|c|c|c|c|c|c|}
\hline \multirow[t]{3}{*}{ Case } & \multirow[t]{3}{*}{ No. } & \multirow[t]{3}{*}{ Model } & \multirow{3}{*}{$\begin{array}{l}\text { Water } \\
\text { depth } \\
(\mathrm{cm})\end{array}$} & \multirow[t]{3}{*}{$\begin{array}{l}\text { Input } \\
\text { wave }\end{array}$} & \multirow{3}{*}{$\begin{array}{c}\text { Input } \\
\text { max. acc } \\
\text { (Gai) }\end{array}$} & \multicolumn{2}{|c|}{$\begin{array}{l}\text { Coef. of friction } \\
\text { for calculation }\end{array}$} & \multicolumn{3}{|c|}{$\begin{array}{c}\text { Relative } \\
\text { displacement }(\mathrm{mm})\end{array}$} \\
\hline & & & & & & \multirow{2}{*}{ Static } & \multirow{2}{*}{ Dymanic } & Obse: & yed & \\
\hline & & & & & & & & DI & D2 & Calculated \\
\hline 1 & 9 & $A^{\star}$ & 0 & $\begin{array}{l}\text { Sine wre } \\
10 \mathrm{~Hz}\end{array}$ & 842 & 0.73 & 0.55 & & 0.22 & 0.73 \\
\hline 1 & 12 & + & , & $\mid \begin{array}{l}\text { Sine wave } \\
20 \mathrm{HZ}\end{array}$ & 740 & 0.76 & 0.55 & 0.05 & 0.07 & 0.08 \\
\hline 1 & 22 & - & . & $\begin{array}{l}\text { Eartha. } \\
\text { weve }\end{array}$ & 682 & 0.59 & 0.52 & 0.26 & 0.26 & 0.29 \\
\hline 5 & 8 & . & $\therefore$ & Sine weve & 690 & 0.68 & 0.53 & 0.40 & 0.41 & 0.26 \\
\hline 5 & 4 & " & . & $\mid \begin{array}{l}\text { Sine wave } \\
10 \mathrm{~Hz}\end{array}$ & 726 & 0.69 & 0.57 & 0.18 & 0.27 & 0.30 \\
\hline 3 & 34 & $B 2$ & - & Sine meve & 573 & 0.57 & 0.49 & 0.46 & 0.45 & 0.36 \\
\hline 4 & 6 & - & 25 & $\begin{array}{l}\text { Šine wave } \\
5 \mathrm{~Hz}\end{array}$ & 130 & 0.45 & 0.34 & 0.15 & 0.15 & 0.08 \\
\hline 6 & 3 & $A^{\star \star *}$ & 0 & $\begin{array}{l}\text { Sine wave } \\
10 \mathrm{~Hz}\end{array}$ & 631 & 0.65 & 0.61 & 0.04 & 0.03 & 0.02 \\
\hline 6 & 12 & * & • & $\mid \begin{array}{l}\text { Sine wave } \\
20 \mathrm{~Hz}\end{array}$ & 650 & 0.61 & 0.56 & 0.02 & 0.01 & 0.02 \\
\hline
\end{tabular}

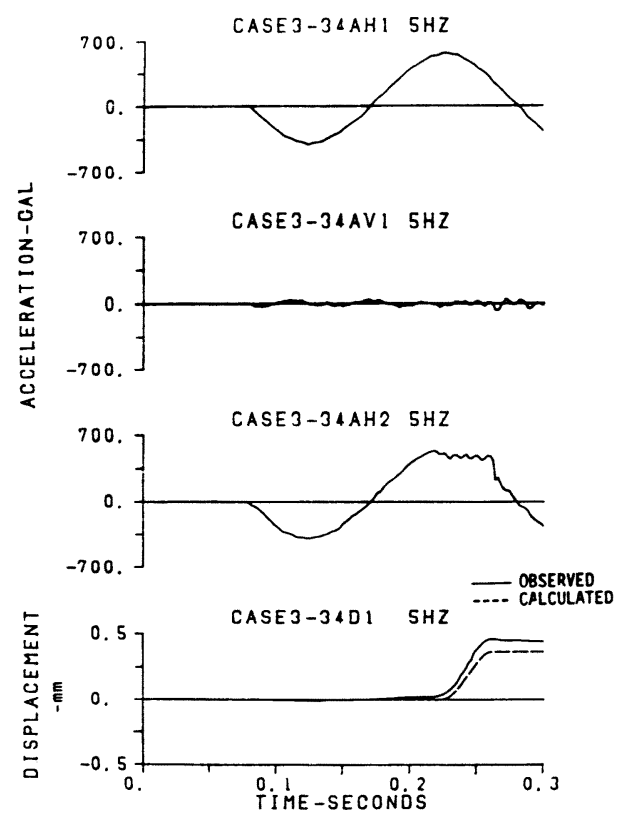

Fig. 14 Calculated and observed relative displacement (Model B 2). 
body divided by acceleration of gravity.

(2) Comparison of observed and calculated results

Table 5 shows the computed results. The time histories of computed and observed sliding displacement are shown in Fig. 14 for the model B 2 on the acrylic sheet and in Fig. 15 for the model $\mathrm{A}$ on the acrylic sheet.

Though there were two computed displacements which were 3 and 0.15 times respectively than observed one, other computed displacements were almost same as observed displacements. Therefore it was concluded that the displacement computing method presented here was valid for the sliding rigid body that does not show a large response. The displacement computing method of a sliding rigid body that shows large reponse will be discussed in the future.

\section{CONCLUSION}

The discussed results are as follows.

(1) According to the shaking table tests an amplitude of model accelerations decreased instantaneously at

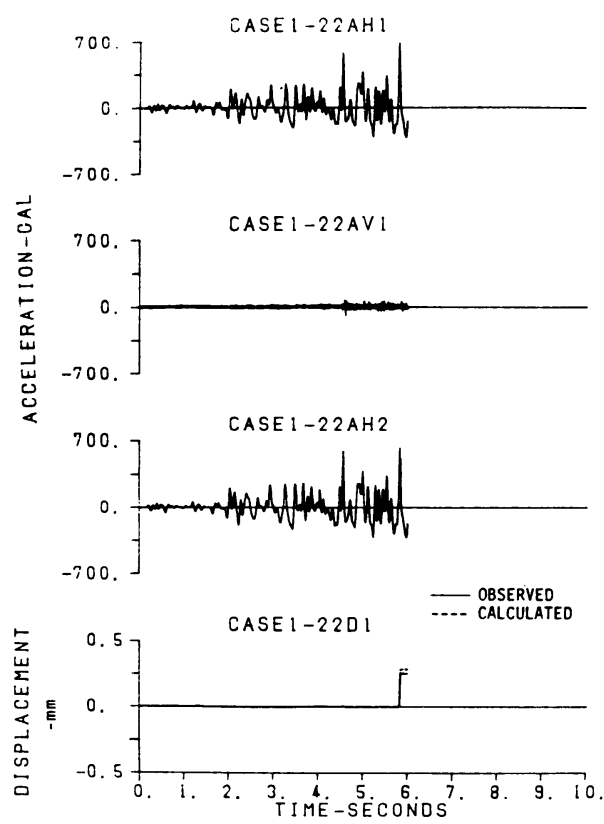

Fig. 15 Calculated and observed relative displacement (Model A). the moment to cause a sliding displacement and remained the same level during sliding (see Fig. 7). Therefore it may be assumed that the coefficient of friction decreases discontinuously from the static value to the dynamic and remains a dynamic value during sliding.

(2) According to the shaking table tests of a rigid body model in the water the coefficients of friction obtained in consideration with the added mass that is twice the hydrodynamic pressure on a side wall of a rigid body divided by acceleration of gravity were nearly same as those of a rigid body model without the water (see Fig. 12). Therefore it may be concluded that the added mass that is twice the hydrodynamic pressure on a side wall of a rigid body divided by acceleration of gravity can be used to calculate the sliding displacement of a rigid body during earthquakes.

(3) The hydrodynamic pressure on a rigid body model decreased instanteneously at the moment to cause a sliding displacement and remained the same level during sliding (see Fig. 8). This waveform of the hydrodynamic pressure was similar to that of the acceleration.

(4) The displacement computing method of a sliding rigid body under earthquake loading was presented. The calculated results in consideration with the above paragraph from (1) to ( 3 ) were likely same as the observed results. Therefore it was concluded that this displacement computing method of a sliding rigid body that does not show a large response is valid (see Table 5, Fig. 14 and Fig. 15).

\section{ACKNOWLEDGMENT}

The authors wish to thank Dr. Hajime Tsuchida, director of structures division, Port and Harbour Research Institute, Ministry of Transport for many helpful discussions.

\section{REFERENCES}

1) Newmark, N. M. : Effects of Earthquakes on Dams and Embankments, Geotechnique, Vol. 15, No. 2, Jan. 1965.

2) Franklin, A.G. and Chang, F. K. : Permanent Displacements of Earth Embankments by Newmark Sliding Block Analysis, Miscellaneous Paper S-71-17, U. S. Army Engineer Waterways Experiment Station, Nov. 1977.

3) Richards, R., Jr. and Elms, D. G. : Seismic Behavior of Gravity Retaining Walls, Proc. of ASCE. Vol. 105, No. GT 4, pp. 449 $\sim 464$, Apr. 1979. 
4) Sim, L. C. and Berrill, J. B. : Shaking Table Tests on A Model Retaining Wall, Proc. S. Pacific Reg. Conf. Earthq. Eng., Wellington, May 1979.

5) Fujino, Y., Sasaki, Y. and Hakuno, M. : Slip of a Friction-Contralled Mass Excited by Earthquake Motions, Bull. Res. Earthq. Inst. , Vol. 53, 1978.

6) Toki, K., Sato, T. and Miura, F. : Separation and Sliding between Soil and Structure during Strong Ground Motion, Proc. of JSCE. No. 302, 1980.

7) Soda, N. : Friction Story, Iwanami Shinsho, 1980.

(Received September 14 1984) 